\title{
EFICIÊNCIA DE MÉTODOS DE LIMPEZA E DESINFECÇÃO NOS LEITOS DAS ENFERMARIAS DE UM HOSPITAL DE TEÓFILO OTONI-MG
}

\section{EFFICIENCY OF METHODS OF CLEANING AND DISINFECTION IN THE BEDS OF THE WARDS OF A HOSPITAL OF TEOFILO OTONI-MG}

\author{
Anderson Luiz Colen \\ Acadêmico, Universidade Presidente Antônio Carlos, BRASIL \\ anderson_luizcolen@hotmail.com \\ Gabriel Rodrigues Oliveira Viana \\ Acadêmico, Universidade Presidente Antônio Carlos, BRASIL \\ gabrielunipacto2015@ hotmail.com \\ Leandro Almeida de Castro \\ Farmacêutico- Especialista em Analises Clinica-UNIPAC \\ leo.acastro@hotmail.com \\ Daniel Azevedo Teixeira \\ Farmacêutico Bioquímico -Doutor em Biocombustíveis. UNIPAC \\ danielteixeira@unipacto.com.br
}

\begin{abstract}
Resumo
O presente trabalho teve como foco realizar um levantamento de dados sobre a limpeza e desinfecção exercida nos leitos das enfermarias (masculina, feminina e infantil) de um hospital de Teófilo Otoni-MG, tendo como objetivo contribuir com o controle de infecção hospitalar, com a busca por realização de novas pesquisas e servir de base ao desenvolvimento de raciocínios que contribuam com a promoção da saúde. A metodologia adotada para a realização do trabalho foi a de análise microbiológica em meio de cultivo Agar hipertônico de manitol, seletivo ao crescimento de Staphylococcus aureus, que através de testes in vitro possibilitou a análise microbiológica de amostras coletadas, sendo identificado $100 \%$ de positividade do microrganismo na enfermaria masculina com superioridade a feminina $75 \%$ e infantil $54 \%$, foi estabelecido a media fatorial para contagem de unidades formadoras de colônias (UFC/g) de Staphylococcus aureus em locais como (piso, paredes, bancada e leitos) das enfermarias, a soma de
\end{abstract}


colônias obtidas nos pontos específicos e leitos resultou na presença de 98,75 e 54 $\mathrm{UFC} / \mathrm{g}$ nas enfermarias masculina, feminina e infantil respectivamente. Foi testada também nas amostras microbiológicas coletadas antes e após a limpeza das enfermarias a eficácia dos produtos (Hipoclorito de sódio 03\%, Álcool a 70\% e iodopovidona (Iodo - PVPI) utilizados pelo hospital e o produto composto Nippo-bac plus®, realizando um comparativo de eficácia, onde o Nippo-bac plus ${ }^{\circledR}$ antes e após a limpeza das enfermarias demonstrou $100 \%$ de eficácia. Com isto, pode-se encontrar melhores métodos para diminuir as possibilidades de risco aos quais os pacientes hospitalizados ficam sujeitos. Ainda, se pode apurar que é possível a partir de prevenção e de ações básicas levar informações aos profissionais de saúde a adotar medidas para reduzir ou exterminar a infecção hospitalar.

Palavras-chave: Limpeza; Desinfecção; Infecção Hospitalar; Staphylococcus aureus.

\begin{abstract}
The objective of this study was to collect data on the cleaning and disinfection of the infants' beds (male, female and child) at a hospital in Teófilo Otoni-MG, with the aim of contributing to hospital infection control, with the search by conducting new research and serving as a basis for the development of reasoning that contributes to health promotion. The methodology adopted for the accomplishment of the work was the one of microbiological analysis in hypertonic agar culture medium of manitol, selective to the growth of Staphylococcus aureus, that through in vitro tests made possible the microbiological analysis of samples collected, being identified $100 \%$ of the positivity of the microorganism in the male ward with $75 \%$ female and $54 \%$ female superior, the factorial was established for counting colony forming units (CFU/g) of Staphylococcus aureus in places such as (floor, wall, bed and bed) of the infirmaries, the sum of colonies obtained at the specific points and beds resulted in the presence of 98,75 and $54 \mathrm{CFU} / \mathrm{g}$ in the male, female and child wards, respectively. The efficacy of the products (sodium hypochlorite 03\%, a 70\% alcohol and PVP-I iodine) used by the hospital and the compound product Nippo-bac plus ${ }^{\circledR}$ were also tested in the microbiological samples collected before and after cleaning of the infirmaries, performing a comparative of effectiveness. With this, better methods can be found to reduce the risk possibilities to which hospitalized patients are subjected. Also, it can be verified that it is possible, from prevention and basic actions to take information to health professionals to adopt measures to reduce or exterminate the hospital infection.
\end{abstract}

Keywords: Cleaning; Disinfection; Hospital Infection; Staphylococcus aureus.

\title{
1. Introdução
}


Há décadas infecções vêm sendo um grande problema à saúde humana pelo mundo, em que a intensificação deste problema ocorre com maior abundancia no âmbito hospitalar, por se tratar de um ambiente propício a foco de contatos e de transmissão de microrganismos (MOREIRA, 1998).

Segundo o Ministério da Saúde, a infecção hospitalar é adquirida após a entrada do paciente no hospital e manifesta-se durante o período de internação ou posterior a alta, desde que seja relacionada à internação ou aos métodos hospitalares. Salienta-se que não sendo somente nos hospitais que ocorra às infecções, a terminologia Infecção adquirida em serviços de Saúde vem sendo considerada mais apropriada (MINISTERIO DA SAUDE, 1998).

Infecção hospitalar é uma temática que ao longo da história vem sendo bastante pesquisada e discutida, no inicio da década 70 com a descrição dos primeiros surtos de infecção no âmbito hospitalar, Staphylococcus aureus foi apontando como o principal agente infeccioso Moreira, 1998. Staphylococcus aureus é um microrganismo de caráter oportunista encontrado na microbiota, em mucosa (oral, bucal e nasal) de seres humanos, quando em contato ao organismo humano ocasiona quadros graves de infecções (BERNARDO et al., 2005).

Ainda na década de 70 houve grandes reformulações a respeito do controle de infecção, aprofundamento de estudo sobre a problemática, ações preventivas, criações de núcleos para o controle da infecção etc. Já no Brasil, surgiram as primeiras Comissões de Controle de Infecção Hospitalar (CCIH). (PEREIRA, 1998).

Porem mesmo com a aplicabilidade de ações desenvolvidas por comissões de controle de infecções hospitalares no decorrer dos anos, a temática infecção hospitalar aparece como alerta em estudos, onde pesquisas realizadas em países desenvolvidos indicam que, ao menos $5 \%$ dos pacientes que dão entrada nos hospitais adquirem uma infecção. (ASHISH, 2008).

No Brasil, pesquisas desenvolvidas em hospitais universitários, ano de 2009, identificou prevalência $8,2 \%$ de infecção hospitalar anual, sendo 149 (29,1\%) pneumonias; 87 (17\%) infecções do trato urinário; 136 (26,6\%) infecções de corrente sanguínea, 47 (9,2\%) infecções de sítio cirúrgico, 57 (11,1\%) infecções de cateter 
central (NOGUEIRA, 2009). Onde mais de 30\% dos casos de infecção no âmbito hospitalar é ocasionada por Staphylococcus aureus (MUNDIM, 2003).

A enfermaria de um hospital é um setor com ampla exposição à microrganismos como Staphylococcus aureus. Local onde ocorre transito de pessoas, prestação de assistência direta e continua a paciente pela equipe de enfermagem, sendo responsável efetuar métodos de esterilização e desinfecção de materiais, uma de suas funções no âmbito hospitalar com auxilio da equipe de limpeza e promover segurança hígida ao setor. (COSTA, 2000).

Deste modo a ANVISA, salienta a relevância do Serviço de Limpeza e Desinfecção de Superfícies em Serviços de Saúde sendo fundamental na prevenção das infecções relacionadas à assistência à saúde, sendo essencial o aprimoramento da utilização de métodos eficientes para promover a limpeza e desinfecção do âmbito hospitalar (_. AGENCIA NACIONAL, 2012).

O papel do profissional farmacêutico é fundamental estabelecendo normas no consumo de antibióticos por meio de análise dos pacientes que utilizaram desses medicamentos e da frequência relativa do emprego de cada princípio ativo, trabalhar junto ao laboratório de análises clínicas com antibiograma na avaliação dos antimicrobianos a respectivas bactérias resistentes, no laboratório de microbiologia, atuar na área epidemiológica, na escolha e manipulação de anti-sépticos, desinfetantes, esterilizantes, produtos que atuam na área de desinfecção e descontaminação e processamento de limpeza, de determinados ambientes e aparelhos hospitalares (BRASIL, 1994).

Diante de tal exposto foi realizado através de uma pesquisa de campo uma analise sobre a eficiência da limpeza e desinfecção adotada e exercida nos leitos das enfermarias (Masculina, feminina e infantil) de um hospital na cidade de Teófilo OtoniMG, objetivando avaliar a eficácia dos métodos e produtos empregados à limpeza e desinfecção dos leitos. Em que por meio de testes in vitro obteve-se um levantamento de dados contendo resultados definidos e mensuráveis quanto à presença de Staphylococcus aureus, em pontos específicos e leitos das enfermarias, resultados quanto à eficácia de produtos saneantes adotados pelo hospital para limpeza e 
desinfecção, comparando-os ao produto Nippo-Bac Plus®, desinfetante hospitalar para superfícies fixas e artigos não críticos: comadres, aparadores, cubas, aparelhos de pressão, entre outros.

\section{Métodos}

\subsection{Classificação da Pesquisa}

A presente pesquisa é de caráter experimental delineada comparativa.

\subsection{Local da pesquisa}

Foram realizadas analises através de testes in vitro de amostras microbiológicas dos leitos das enfermarias (masculina, feminina e infantil) de um hospital de Teófilo Otoni-MG, a fim de testar a eficácia dos métodos de limpeza e desinfecção adotados e executados nas enfermarias do hospital, analisando a presença de Staphylococcus aureus em caráter quali-quantitativo e a eficácia dos produtos Álcool a 70\%, Hipoclorito de Sódio 03\% e Iodo PVP-I utilizados pelo hospital no processo de desinfecção antes e após a limpeza realizando um comparativo de eficácia com o produto Nippo-bac Plus®.

\subsection{Coletas de Amostras Microbiológicas}

As análises microbiológicas foram realizadas entre os meses de Abril e Maio de 2019, em que foi utilizado o método laboratorial, cultivo microbiológico em meio Ágar hipertônico de Manitol (utilizado em placas de Petri para cultivo de Staphylococcus aureus). Foram coletadas amostras microbiológicas em triplicata de um leito de cada enfermaria do hospital, de pontos específicos como: piso, parede, maca e bancada. Utilizando uma placa com o meio de cultivo Agar Manitol e Swab estéril para cada ponto específico de cada enfermaria do hospital. Os Swab estéril foram umedecidos em solução salina $(\mathrm{NaCl}$ 0,9\%) e logo utilizados para a coleta de amostras microbiológicas 
de cada ponto especifico. Após a coleta, as amostras contidas nos Swab foram inoculadas nas placas de Petri e devidamente identificadas, logo depois transportadas em uma caixa térmica com temperatura entre $2^{\circ}$ e $8^{\circ}$ para o laboratório de análises clínicas da Faculdade Presidente Antonio Carlos, onde foi encubadas na estufa a temperatura $37^{\circ}$.

\subsection{Análises Microbiológicas}

Após 48 horas de acondicionamento foram analisadas as placas contendo amostras microbiológicas de pontos específicos das enfermarias, analisando o possível crescimento de Sthaphylococcus aureus, quantificando esse crescimento e testando nas próprias placas com amostras microbiológicas dos produtos de limpeza e desinfecção adotados pelo hospital consequentemente testando sua eficácia. Considerou-se as coletas em triplicata, em quatro pontos diferentes de cada local analisado e com reprodução da análise em duas apresentações, portanto, foi estabelecido a média das colônias identificadas na análise fatorial de 3x4x2.

\subsection{Produtos Utilizados}

\section{Álcool 70\%}

O álcool etílico e isopropílico são desinfetantes de nível intermediário geralmente empregado na desinfecção de superfícies, instrumentos e pele como antisséptico. O álcool provoca a desnaturação de proteínas e decomposição de gorduras possibilitando a ação antimicrobiana, sendo ineficaz na presença de matéria orgânica, funcionando como barreira mecânica contra os microrganismos. As vantagens da desinfecção do álcool a $70 \%$ e que ele tem uma rápida ação bactericida, pequena irritabilidade, baixo custo, incolor e não deixa resíduos, desvantagem é que não elimina esporos, tem baixa atividade na presença de matéria orgânica, danifica plástico, borracha e acrílico (VENTURELLI et al., 2018). 


\section{Hipoclorito de Sódio $03 \%$}

Uma grande característica na ação do hipoclorito é a sua concentração, que quanto mais elevado o tempo de exposição do produto sobre a superfície a ser desinfetada maior será a sua eficácia, sendo indicado seu uso em superfícies, artigos não metálicos, artigos de berçários, lactários e no tratamento de água (CASTRO, 2014).

Age destruindo a cápsula bacteriana de proteção e oxidação do protoplasma celular realizando assim sua função sanitizante, forma também cloraminas tóxicas que modificam a permeabilidade celular o que não deixa a regeneração enzimática acontecer. Suas vantagens e que tem um baixo custo e eficaz em varias diluições, fácil de preparar. Mais por ser altamente corrosivo danifica peças de metais, borracha e reage com matéria orgânica irritando a pele, mucosas e vias respiratórias dos responsáveis pela sua manipulação e uso (NASCIMENTO et al., 2010).

\section{Iodo PVP-I}

Sua ação para eliminação dos microrganismos e a desnaturação protéica, a capacidade de incapacitar a síntese de proteínas por oxidação dos aminoácidos e adição de iodo a ácidos graxos insaturados alterando as propriedades físicas dos lipídeos, por interagir com as ligas duplas dos fosfolipídios, rompendo a parede celular e havendo perda do material intracelular. Sua vantagem e que são bactericidas, viricidas e fungicidas, ativo contra Mycobacterium Sp. além de ter um bom spectro de ação. Suas desvantagens e que tem menos atividade contra esporos e na presença de matéria orgânica não tem um bom desempenho e pode manchar algumas superfícies onde for aplicado (RUI et al., 2011).

\section{Nippo-Bac Plus®}

O Nippo-Bac Plus® e um desinfetante de altíssima diluição desenvolvido especialmente para o ambiente hospitalar, com indicação para desinfecção de piso, 
paredes, mobílias e superfícies fixas em geral atendendo a áreas não criticas, semicriticas e criticas. Ação comprovada contra Pseudomonas aeruginosa, Sthapylococcus aureus e Salmonella, atuam também em cepas como Klebsiella pneumoniae carbapenemase (KPC), Enterococcus faecium, Listeria monocytogenes, Escherichia coli, Acinetobacter baumannii, Aspergillus níger, Candida albicans, Bacilus subtillis, Clostridium difficile e Clostridium sporogenes.

Os princípios ativos principais são o Cloreto de Didecil Dimetil amônio - $5^{\mathrm{a}}$ geração - 37\% (Quartenario Di-Decilico) e o Cloridrato de Polihexametilenobiguanida (PHMB) $-4 \%$. O Quartenario Di-Deciclico é responsável pela difusão através da parede celular, ligação com a membrana citoplasmática e rompimento da mesma, perda de íons $\mathrm{K}+$ e outros constituintes do citoplasma e precipitação do conteúdo celular e sua consequente morte eliminando os microrganismos. O PHMB e atraído para a membrana citoplasmático, onde causa a perda de substancias vitais de baixo peso molecular (tais como íons de potássio e cálcio e a inibição de enzimas responsáveis pela união da membrana, tais como a ATPase.), falha no mecanismo de defesa da célula e a ruptura da parede celular o que leva a perda de substancias macromoleculares e a precipitação do conteúdo celular.

O Nippo-Bac Plus® e indicado para desinfecção de artigos não críticos e superfícies fixas, com validade de 24 meses sem estar diluído. Podendo ser diluído em duas concentrações diferentes 1:500 e 1:200, na diluição de 1:500 sua estabilidade é de 30 dias já a diluição de 1:200 é indicada para o uso na presença de matéria orgânica (secreções), pela concentração do produto ser maior no diluente, apresenta um leve efeito de detergência.

\section{Resultados e Discussão}

Foram analisadas as placas em meio de cultura Agar Manitol com amostras microbiológicas de pontos específicos (piso, parede, bancada e leito), observando nas mesmas o crescimento de UFC (unidades formadoras de colônia) de Sthaphylococcus aureus. 
Unidades formadoras de colônia fundamentam-se na capacidade de reprodução microbiana em meios de cultura apropriados e na temperatura adequada ao seu crescimento. Após um período de 24 a 48 horas ocorre à multiplicação microbiana atingindo milhões de bactérias, a ampla quantidade das mesmas acumula-se em um único lóculo da placa formando colônias visíveis a olho nu em que os resultados são descritos como Unidade Formadora de Colônia ou (UFC) em peso, volume, área e etc. (OSOWSKY et al., 2001).

\subsection{Resultados das Analises Microbiológicas}

Foi identificado o índice em porcentagem da positividade para a presença de Sthaphylococcus aureus, obtendo altos valores percentuais dos microrganismos nos três setores analisados do hospital, em que a enfermaria masculina possui lugar de destaque com $100 \%$ para a presença de Sthaphylococcus aureus sobre a feminina e infantil como demonstra o Gráfico Um.

Gráfico Um: Crescimento de Sthaphylococcus aureus nas Enfermarias de um Hospital de Teófilo Otoni - MG. 




Fonte: Dados da própria Pesquisa.

Sendo os dados obtidos relacionados a estudos como o de Oie et al.,(2002) onde nas maçanetas das enfermarias houve $27 \%$ de positividade para Sthaphylococcus aureus. Já em um estudo realizado em um hospital de Uberlândia por Carvalho, (2005) é relatada a positividade de $40 \%$ em superfícies de enfermarias do hospital.

Dados de extrema relevância, segundo Kowalsky et al., (2005) entre $30 \%$ a 50 $\%$ dos pacientes no âmbito hospitalar contraem Sthaphylococcus aureus, onde os valores são superiores em colaboradores do hospital.

O que eleva os índices percentuais de Sthaphylococcus aureus encontrados nas enfermarias masculina, feminina e infantil como um dado preocupante, tendo em vista o destaque do microrganismo patogênico na etiologia das infecções hospitalares por conter versatilidade em adquirir resistência aos antimicrobianos (ALMEIDA et al., 2007).

Através da soma dos resultados obtidos ao crescimento dos pontos específicos das enfermarias demonstrados no gráfico um, obteve-se o resultado da enfermaria com maior índice de UFC/g, sendo a enfermaria masculina com $98 \mathrm{UFC} / \mathrm{g}$ de crescimento, seguida da enfermaria feminina com 75 e infantil com 54 como demonstrado no Gráfico Dois. 
Gráfico Dois: Unidades Formadoras de Colônias/g em Diferentes Ambientes

Hospitalares nas Enfermarias de um Hospital de Teófilo Otoni - MG.

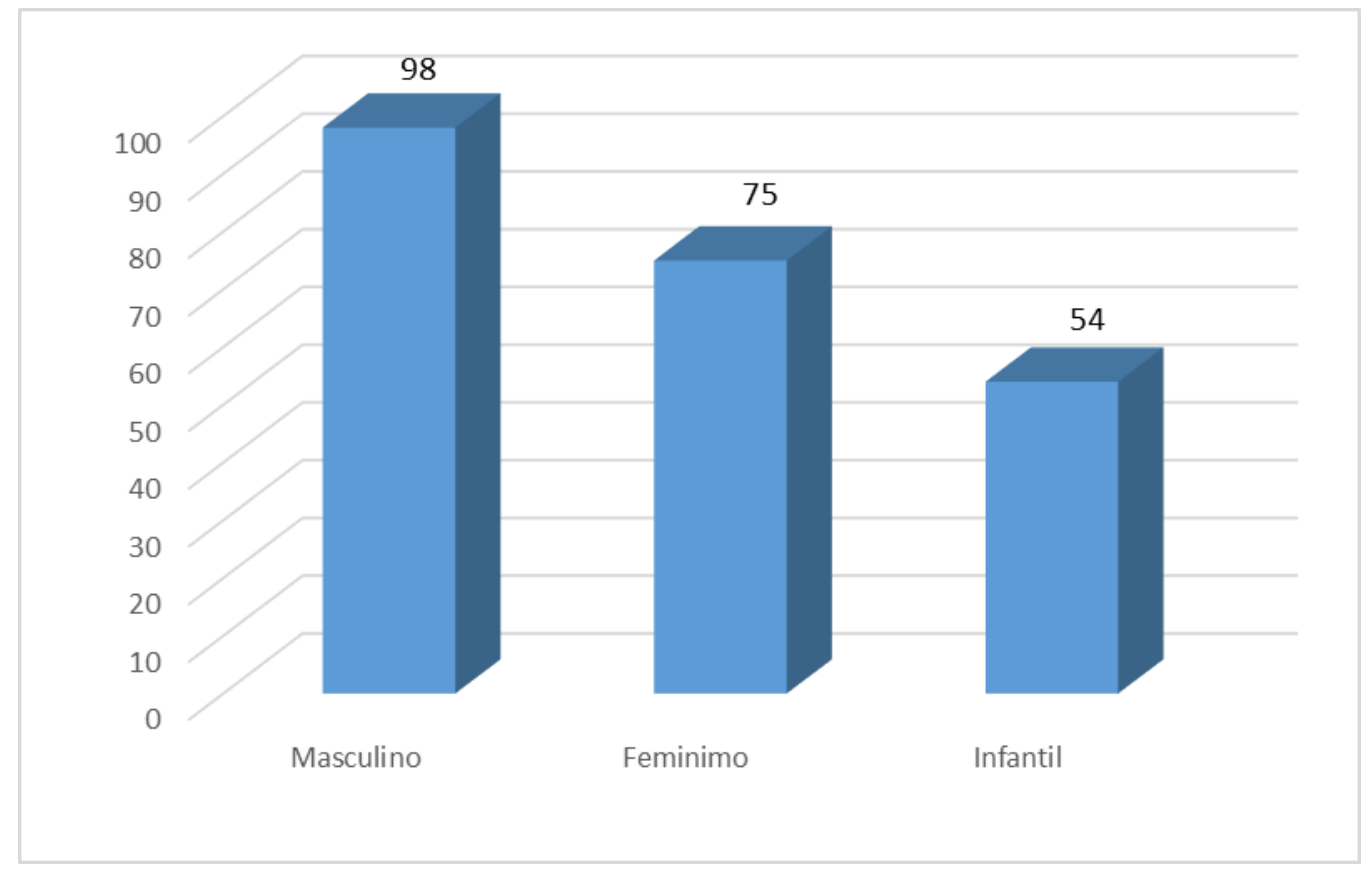

Fonte: Dados da própria Pesquisa.

Os valores de UFC/g encontrados no gráfico dois foi comparado ao estudo realisado por Teixeira et al. (2017) onde analisaram a presença de UFC/g de Sthaphylococcus aureus em setores de um hospital em uma cidade no vale do Mucuri, sendo identificado $73 \mathrm{UFC} / \mathrm{g}$ na enfermaria masculina, $2 \mathrm{UFC} / \mathrm{g}$ na pediatra, não havendo crescimento de colônias na enfermaria feminina, houve superioridade numérica de UFC na enfermaria masculina em ambas as pesquisas, sendo relatado no presente estudo o crescimento expressivo de colônias nas enfermarias feminina e infantil.

Nas placas contendo amostras microbiológicas de pontos específicos dos leitos das enfermarias, obteve-se o crescimento de UFC para Sthaphylococcus aureus em todos os pontos testados, sendo predominantes os valores de crescimento de UFC nos pontos específicos e leitos da enfermaria masculina como demonstrado no Gráfico Três. 
Gráfico Três: Unidades Formadoras de Colônia/g em Superfícies Fixas nas Enfermarias de um Hospital de Teófilo Otoni - MG.

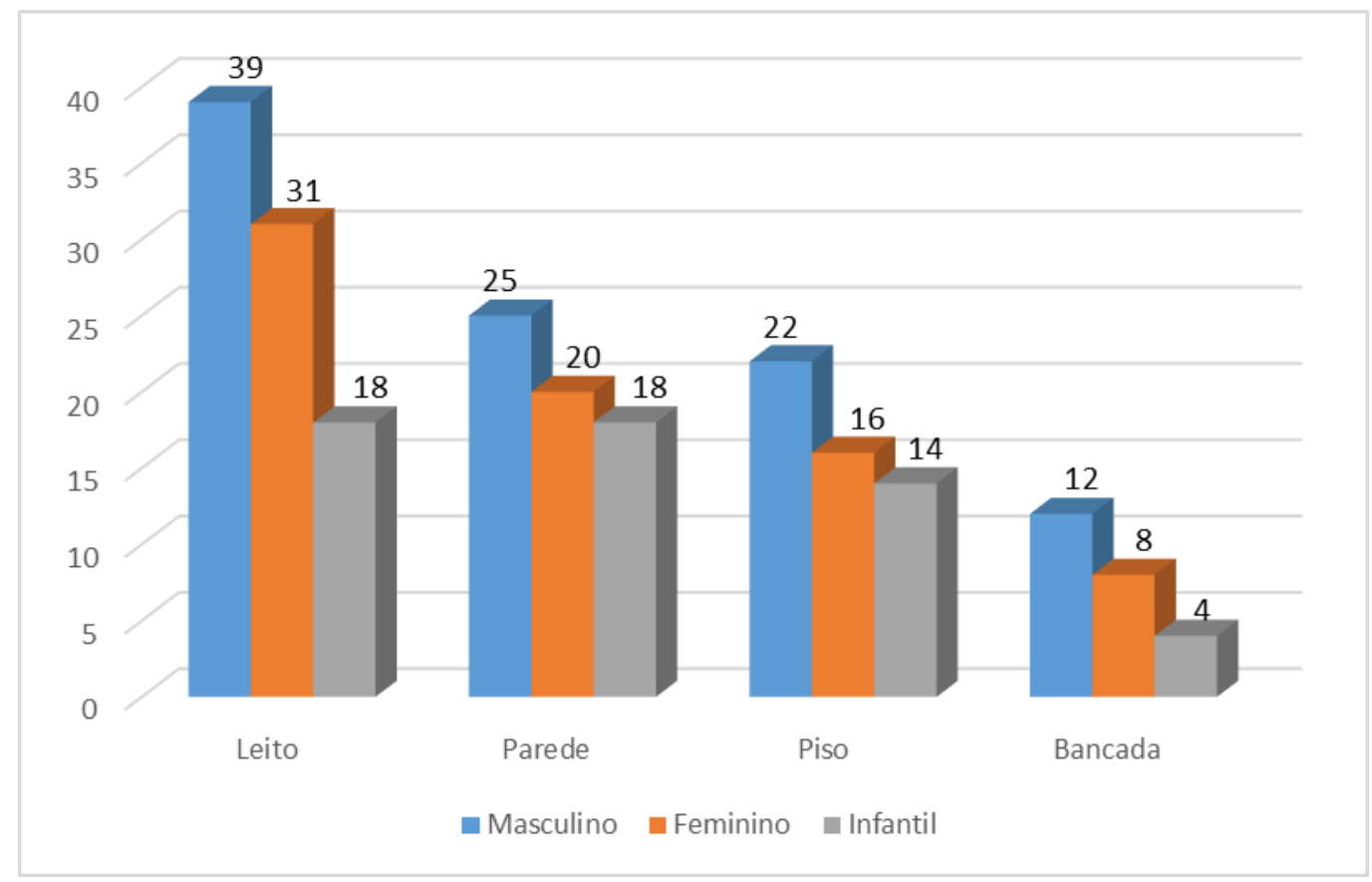

Fonte: Dados da própria Pesquisa.

A presença de UFC nos pontos específicos e leitos podem indicar ineficácia na aplicação de produtos e métodos de limpeza e desinfecção. Sendo a presença de focos contaminantes em locais visualmente limpos uma fonte de disseminação de patógenos, onde a não há evidencia de sujidade a olho nu, fazendo com que métodos de limpeza eficazes sejam ignorados, e que a locomoção intensa de indivíduos no âmbito hospitalar em contato a partes físicas, objetos e pacientes possibilita a disseminação de microrganismos (OLIVEIRA, 2010).

\subsection{Resultados da Eficácia dos Produtos Utilizados}

Foi realizada a analise dos produtos utilizados na limpeza e desinfecção dos leitos como mostrado no Gráfico Quatro, onde foi utilizado o Nippo-Bac Plus®, Álcool 
a 70\%, Hipoclorito de Sódio 03\% e o Iodo PVP-I. Sendo Nippo-Bac Plus® o que teve melhor eficiência contra os microrganismos com percentual de $100 \%$.

Gráfico Quatro: Percentual de Eficiência por Desinfetantes em Leitos de um Hospital de Teófilo Otoni.

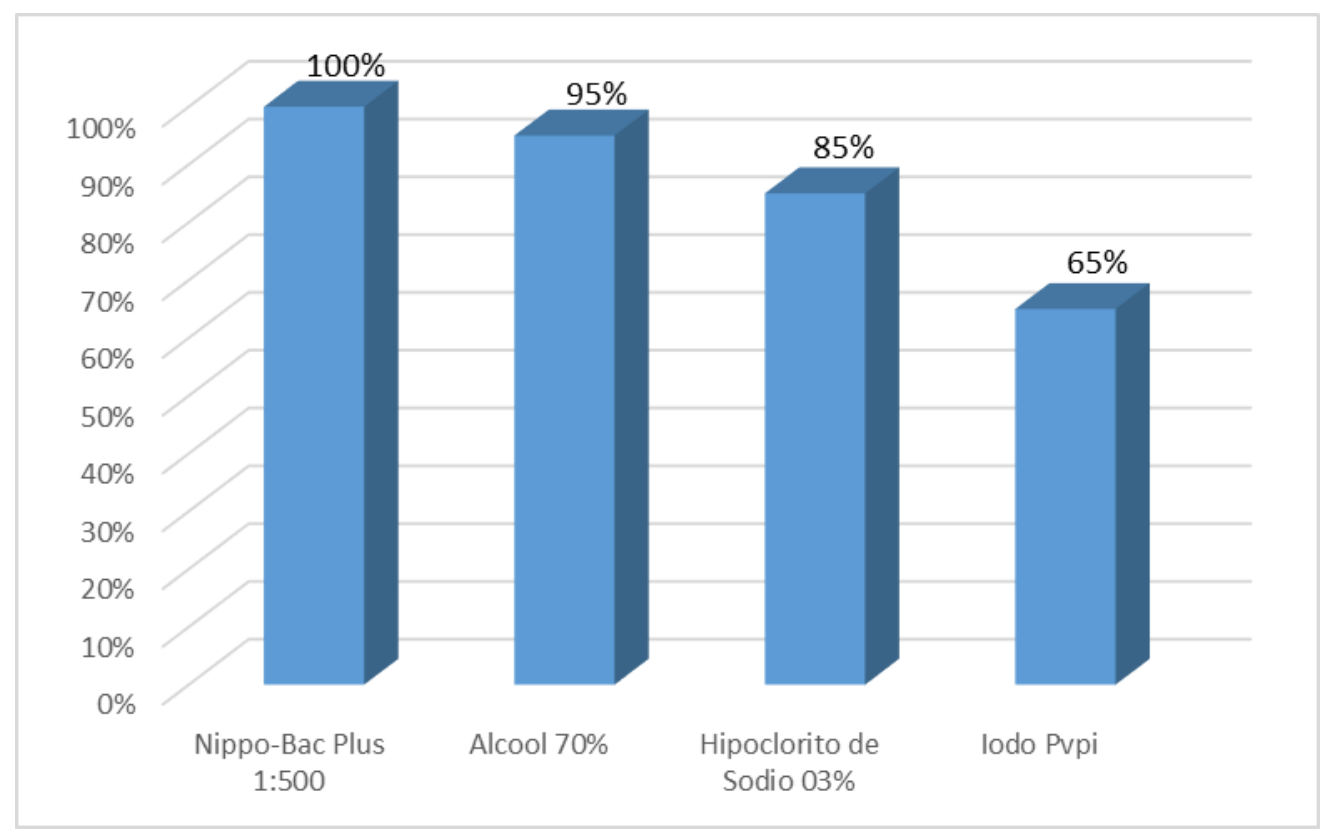

Fonte: Dados da própria Pesquisa.

O álcool a $70 \%$ teve uma percentual de $95 \%$ de eficiência, comparado com o estudo de Venturelli et al.(2018), onde indica que o uso de álcool a 70\% para desinfecção de superfícies eliminou as bactérias impedindo o crescimento bacteriano.

Já o Hipoclorito de Sódio $03 \%$ mostrou uma eficiência de $85 \%$ contra os microrganismos comparado com o estudo de Scur et al. (2014) para Sthaphylococcus aureus, na ausência de matéria orgânica, o Hipoclorito de Sódio 03\% apresenta as maiores reduções nas contagens de UFC (entre 90\% e 100\%). O Iodo PVP-I mostrou um resultado de $65 \%$ frente aos microrganismos mostrando ser o menos eficiente em comparação com outros produtos, comparando com o estudo de Scur et al. (2014), 
indica que o Iodo PVP-I apresenta as maiores contagens de UFC, inibindo o crescimento de Sthaphylococcus aureus entre 59\% a $75 \%$.

Também foi realizada á analise para saber qual produto mostra uma desinfecção mais eficiente antes e após a limpeza dos leitos como mostrado no Gráfico Cinco, entre os produtos testados o que se mostrou mais eficaz foi o Nippo-Bac Plus ${ }^{\circledR}$ dando um resultado de $100 \%$ antes e após a limpeza.

Grafico Cinco: Percentual de Eficiencia de Desinfecção de Leitos Antes e Após Limpeza com Agua e Sabão.



Fonte: Dados da própria Pesquisa.

Após a limpeza houve uma potencialização da desinfecção por não conter matéria orgânica o que já foi relatado em outros estudos como os de Scur et al. (2014). Sendo comprovado por Favero e Bond, (1991), onde descreve que a matéria orgânica impede que os microrganismos entrem em contato com os desinfetantes. O Nippo-Bac Plus ${ }^{\circledR}$ mesmo sem realizar a limpeza consegue atingir uma eficiência de $100 \%$, por ser um desinfetante a base de Amônia Quaternária combinado com Biguanida Polimérica tendo a ação de limpar e desinfetar em uma única etapa (SANTOS JUNIOR, 2018). 


\section{Conclusão}

Dentre os produtos utilizados para desinfecção hospitalar o Nippo-Bac Plus® se mostrou o mais eficaz por conseguir $100 \%$ de desinfecção mesmo em uma superfície suja, por apresentar dupla função de detergência e desinfetante, evitando a proliferação de microrganismos nas superfícies. Com o levantamento dos dados concluímos que para manter um ambiente Hospitalar hígido não podemos apenas levar em consideração o uso de desinfetantes mais também treinamentos para conscientização dos funcionários em realizar a tarefa de limpeza tanto de partes físicas como de artigos não críticos com total desempenho, utilizando os desinfetantes mesmo em partes do local onde não apresenta sujidade visível.

Além disso, o estudo mostra que o percentual do microrganismo Sthaphylococcus aureus na enfermaria masculina e bem mais elevado do que na feminina e infantil, sendo assim necessário um maior cuidado para com a limpeza na enfermaria masculina a fim de evitar o aumento de infecções hospitalares e da contaminação de outros setores.

O farmacêutico é um profissional de grande importância para a prevenção e controle das infecções hospitalares, uma vez que juntamente com toda a equipe do hospital, deve participar na padronização dos antimicrobianos e dos agentes antisépticos, desinfetantes e esterilizantes, podendo implementar ações relacionadas tanto ao diagnóstico de surtos de infecções, quanto ao aparecimento de cepas multiresistentes. Estes procedimentos visam melhorar a qualidade da prestação de serviço ao usuário do estabelecimento de saúde.

\section{Referencias}

Agência Nacional de Vigilância Sanitária: Segurança do paciente em serviços de saúde: limpeza e desinfecção de superfícies/Agência Nacional de Vigilância

Sanitária.Brasília: Anvisa, Cap. 7, p.66-81. 2012. Acesso: 26 de Maio 2018. 
ALMEIDA, Maria Inez et al. Prevalência e perfil de sensibilidade de amostras de Staphylococcus aureus isoladas de casos clínicos de infecções hospitalares. Revista Eletrônica de Enfermagem, v. 9, n. 2, 2007. Acesso: 25 de Maio 2019.

BERNARDO, Wagner Luis de Carvalho et al. Staphylococcus aureus ampicillinresistant from the odontological clinic environment. Revista do Instituto de Medicina Tropical de São Paulo, v. 47, n. 1, p. 19-24, 2005. Acesso: 08 de Maio 2019.

BRASIL. Ministério da Saúde. Coordenação de Controle de Infecção Hospitalar. Processamento de artigos e superfícies em estabelecimentos de saúde. $2^{\circ}$ ed. Brasília, 1994. Acesso: 25 de Maio de 2019.

CARVALHO, Karinne Spirandelli et al. Contaminação de superfícies em enfermarias de pacientes com infecções por Staphylococcus aureus no Hospital de Clínicas na Universidade Federal de Uberlândia. 2005. Acesso: 04 de Maio 2019

CASTRO,A,L Análise Microbiológica Dos Ambientes Das Salas De Observação Do Hospital Terciário Do Sus No Município De Teófilo Otoni - MG. 2014. 55p Fundação Presidente Antônio Carlos - Fupac, Teófilo Otoni, 2014. Acesso: 25 de Maio 2019

COSTA, Tânia Maria Picardi Faria; CARVALHO, Daclé Vilma. Infecção hospitalarconceito de uma equipe de enfermagem. REME rev. min. enferm, v. 4, n. 1/2, p. 1620, 2000. Acesso: 17 de Abr. 2019.

DE OLIVEIRA, Adriana Cristina; DAMASCENO, Quésia Souza. Superfícies do ambiente hospitalar como possíveis reservatórios de bactérias resistentes: uma revisão. Revista da Escola de Enfermagem da USP, v. 44, n. 4, p. 1118-1123, 2010. Acesso: 18 de Mai 2019.

FAVERO, Martin S. Sterilization, disinfection, and antisepsis in the hospital. Manual of clinical microbiology, p. 183-200, 1991. Acesso: 02 de Jun. 2019. 
KOWALSKI, Todd J.; BERBARI, Elie F.; OSMON, Douglas R. Epidemiology, treatment, and prevention of community-acquired methicillin-resistant Staphylococcus aureus infections. In: Mayo Clinic Proceedings. Elsevier, 2005. p. 1201-1208. Acesso: 15 de Mai 2019.

Ministério da Saúde. Portaria n 2616/MS/GM, de 12 de maio de 1998. Dispõe sobre a obrigatoriedade de Programa de Controle de Infecção Hospitalar e sua Estrutura e Atividades. Diário Oficial da União. Brasília: DF, 1998. Acesso: 17 de Mar 2019.

MOREIRA, M. et al. Efeito da infecção hospitalar da corrente sanguínea por Staphylococcus aureus resistente à oxacilina sobre a letalidade e o tempo de hospitalização. Rev Assoc Med Bras, v. 44, n. 4, p. 263-8, 1998. Acesso: 20 de Set 2019.

MUNDIM, Guilhermo Justino et al. Avaliação da presença de Staphylococcus aureus nos leitos do Centro de Terapia Intensiva do Hospital Escola da Faculdade de Medicina do Triângulo Mineiro, em relação à posição no colchão antes e após a limpeza. Rev. Soc. Bras. Med. Trop, v. 36, n. 6, p. 685-688, 2003. Acesso: 20 de Mai 2019.

NASCIMENTO, Henry Mendes; DELGADO, DA BARBARIC; BARBARIC, Ivana Filomena. IF Avaliação da aplicação de agentes sanitizantes como controladores do crescimento microbiano na indústria alimentícia. Revista Ceciliana, v. 2, n. 1, p. 11-13, 2010. Acesso: 26 de Mai 2018.

NOGUEIRA, Paula Sacha Frota et al. Perfil da infecção hospitalar em um hospital universitário. Rev. enferm. UERJ, v. 17, n. 1, p. 96-101, 2009. Acesso: 26 de Out 2018. 
OIE, S.; HOSOKAWA, I.; KAMIYA, Akira. Contamination of room door handles by methicillin-sensitive/methicillin-resistant Staphylococcus aureus. Journal of Hospital Infection, v. 51, n. 2, p. 140-143, 2002. Acesso: 28 de Nov 2018.

OSOWSKY, Jefferson; GAMBA, Humberto Remigio. Sistema automático para contagem de colônias em placas de Petri. Revista Brasileira de Engenharia Biomédica, v. 17, n. 3, p. 131-139, 2001. Acesso: 25 de Maio 2019.

PEREIRA, Milca Severino et al. A infecção hospitalar e suas implicações para o cuidar da enfermagem. Texto \& Contexto Enfermagem, v. 14, n. 2, p. 250-257, 2005. Acesso: 24 de Out 2018.

RUI, Bruno Rogério et al. Principais métodos de desinfecção e desinfetantes utilizados na avicultura: Revisão de literatura. Revista científica eletrônica de medicina veterinária. Garça-SP, Ano IX, n. 16, 2011. Acesso: 14 de Abr 2018.

SANTOS-JUNIOR, Aires G. et al. Effectiveness of Surface Cleaning and Disinfection in a Brazilian Healthcare Facility. The open nursing journal, v. 12, p. 36, 2018. Acesso: 02 de Jun 2019.

SCUR, MAYARA CAMILA et al. Atividade in vitro de desinfetantes comerciais no controle de duas espécies de bactérias de interesse avicola. Boletim de Indústria Animal, v. 71, p. 147-153, 2014. Acesso: 15 de Dez 2018.

TEIXEIRA. A.D, HOTT. C.R, HONORATO. M, FURTADO. V.V.H,ONOFRI.L, LEANDRO ALMEIDA DE CASTRO.A.L: Análise Microbiológica Dos Ambientes Das Salas De Observação De Um Hospital No Vale Do Mucuri -MG..Revista Multidisciplinar do Nordeste Mineiro. Teófilo Otoni:UNIPAC.p.318-319,2017, Acesso: 24 de Fev 2019. 
VENTURELLI, Alessandre Cicero et al. Avaliação microbiológica da contaminação residual em diferentes tipos de alicates ortodônticos após desinfecção com álcool 70\%. Rev Dental Press Ortodon Ortop Facial (Maringá), v. 14, n. 4, p. 43-52, 2009. Acesso: 28 de Mai 2019.

WANNMACHER, Lenita; FUCHS, Flávio D.; FERREIRA, Maria B.C. Anti-sépticos e Desinfetantes. Farmacologia Clínica: Fundamentos da terapêutica racional. 3. ed. Rio de Janeiro: Guanabara Koogan, 2006. Acesso: 23 de Maio 2019.

JHA, Ashish K. (Ed.). Summary of the evidence on patient safety: implications for research. World Health Organization, 2008. Acesso: 07 de Jul 2018. 